\title{
Distribution of enteroviruses in hospitalized children with hand, foot and mouth disease and relationship between pathogens and nervous system complications
}

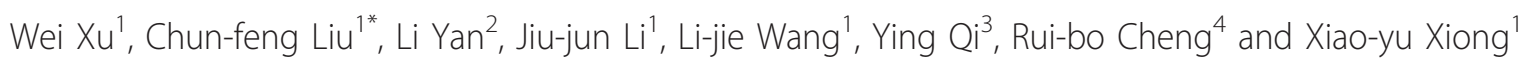

\begin{abstract}
Background: To explore the relationship between enteroviruses and hospitalized children with hand, foot and mouth disease (HFMD) complicated with nervous system disease. 234 hospitalized HFMD patients treated in Shengjing Hospital, Liaoning Province were analyzed retrospectively. Based on the presence and severity of nervous system disease, the patients were grouped as follows: general patients, severely ill patients, critically ill patients and fatal patients. Based on the detected pathogen, the patients were grouped as follows: Enterovirus 71 (EV71) infection, coxsackie A16 (CA16) infection and other enterovirus (OE) infection.

Results: Of the 423 hospitalized patients, most were admitted in July 2010(129/423, 30.5\%). Enteroviruses were detected in 177(41.8\%). 272/423 patients were male (64.3\%), and fatal patients had the greatest proportion of male patients $(p<0.05)$. EV71 infection was found in 89/423 patients (21\%). CA16 infection was detected in 8/423 patients (16.1\%). Compared to group CA16, patients in group EV71 were hospitalized earlier, and the duration of hospitalization was longer $(p<0.05)$. Of the 92 patients with nervous system damage, 65 were infected with EV71 and 19 were infected with CA16. Among these CA16 infected patients, 2 had brainstem encephalitis and 1 had AFP. There were more patients with nervous system dysfunction in group EV71 than in groups CA16 or OE $(p<$ 0.05). The 5 fatalities all occurred in group EV71 patients $(p<0.05)$. Infection with EV71 was most likely to cause neurogenic pulmonary edema $(p<0.05)$. Patients in group EV71 had a higher rate of suffering from coma and limb movement disorder than patients in groups CA16 or OE $(p<0.05)$.

Conclusion: The disease progresses faster in EV71-infected HFMD patients. These patients are more likely to suffer nervous system damage, neurogenic pulmonary edema, severe sequelae or death. CA16 and other enteroviruses can also cause HFMD with severe nervous system complications.
\end{abstract}

Keywords: EV71, CA16, HFMD, Pathogen, Children, Nervous system complication

\section{Background}

Since first reported by Robin Son in 1958 [1], numerous widespread outbreaks of hand, foot and mouth disease (HFMD) have occurred in eastern and southeastern Asia, including Singapore [2], South Korea [3], Malaysia [4], Japan [5], Vietnam [6], mainland China $[7,8]$ and Taiwan $[9,10]$. HFMD was first reported in mainland

\footnotetext{
* Correspondence: xuw@sj-hospital.org

'Department of Pediatrics, Shengjing Hospital of China Medical University, Shenyang 110817, China

Full list of author information is available at the end of the article
}

China in 1981; since then it has prevailed in most provinces of China. Nationwide HFMD outbreaks have occurred in China since 2008, with most of the cases affecting children $\leq 5$ years of age [11]. After this event HFMD has been made a nationally notifiable disease. Despite nationwide effort, 1,795,336 cases were diagnosed annually in 2010 with 905 deaths. HFDM is a common infectious disease that can be caused by more than 20 different enteroviruses, and the symptoms are generally mild and self-limited. Its main manifestations are fever, rash and ulcers in areas such as the oral
C Biomed Central

() 2011 Xu et al; licensee BioMed Central Ltd. This is an Open Access article distributed under the terms of the Creative Commons Attribution License (http://creativecommons.org/licenses/by/2.0), which permits unrestricted use, distribution, and reproduction in any medium, provided the original work is properly cited. 
mucosa and the hands, feet and buttocks. A small proportion of children patients can experience severe complications, including encephalitis, pneumonia, myocarditis, brain-stem encephalitis and acute flaccid paralysis (AFP). High mortality and severe sequelae can be anticipated when the disease is complicated by neurogenic pulmonary edema, rapid disease progression $[12,13]$. HFMD has a disease burden as severe as that imposed by any other pediatric infectious disease and has already received considerable attention from all health sectors at both national and local levels.

Unlike most infectious diseases, it is very difficult to distinguish between the possible pathogens (Enterovirus 71 and Coxsackie A16) in a clinical context, possibly because EV71 and CA16 are closely related. Enterovirus 71 (EV71) and coxsackie A16 (CA16) are small, nonenveloped, positive-stranded RNA viruses that belong to human enterovirus species A, genus Enterovirus, family Picornaviridae. Human EV71 and CA16 are two major pathogens of HFMD in children. These viruses can also cause many other diseases, many of which manifest as herpes angina or flu-like symptoms [14]. Together with CA7 and CA14, these viruses form a distinct genetic subgroup within cluster A of the genus Enterovirus [15]. Recent studies reported that severe nervous system damage happened more in patients infected with EV71. Some reports further suggest that despite the close genetic relationship between EV71 and CA16, only EV71 has the potential to cause neurological disease in acute infection $[16,17]$; however, we disagree with this statement. This report summarizes the clinical manifestations of disease and the distribution of pathogens in HFMD patients, based on patients whose cases were complicated by nervous system disease.

\section{Results}

In 2010, our hospital treated a total of 6,027 cases of pediatric HFMD. Among these, 423 patients (7.0\%) were hospitalized. Hospital stay lasted from 1 to 101 days (median 9 days). 78 patients were referred to PICU with the stay in PICU lasting 1 to 101 days (median 18 days). The overall patient ages ranged from 3 months to 12.5 years, with an average age of 2.71 years.

\section{Demographic characteristics and clinical manifestations}

The 423 patients hospitalized with HFMD were mainly admitted between May and September. Within that period, most patients $(129 / 423,30.5 \%)$ were admitted in July. August and June followed, with 85/423 (20.1\%) and $80 / 423(18.9 \%)$, respectively. Among all admitted patients, 189/423 (44.7\%) were general patients, 197/423 (46.6\%) had severe clinical manifestations, $28 / 423$ (6.6\%) were critically ill and 9/423 (2.1\%) died. The severely ill, critically ill and fatal cases were most frequently seen in
June, July and August. July had the greatest number of severe cases (54/197, 27.4\%). The number of critically ill patients was equally distributed between July and August $(7 / 28,25 \%)$. An equal number of fatalities occurred in June and July (3/9, 33.3\%). A detailed distribution is shown in Figure 1.

The examination of throat swab and/or stool specimens from these 423 patients revealed the presence of a viral pathogen in 177 cases (41.84\%). Among the 177 patients, there were 85 general patients, 71 severely ill patients, 16 critically ill patients and 5 deaths. There was no significant difference in the pathogen detection rate across groups $(p>0.05)$. The overall patient ages ranged from 3 months to 12.5 years, with an average age of 2.71 years. There were significant differences in the average ages among the 4 groups $(p<0.05)$. Among general, severely ill and critically ill groups, patients who had experienced more severe symptoms had more little ages, whereas the group of patients who died showed less significant difference in age compared to the other three groups. Male preferences were detected in the group with severe disease. The proportion of patients from rural areas was 268/423 (63.3\%), but regional differences were not apparent among severe cases $(p>$ $0.05)$. Patients in the group with general disease were hospitalized later than those in other 3 group $\mathrm{t}(p<$ $0.05)$. The time for patients in the group with critically disease stayed in hospital was the longest $(p<0.05)$. The rate of critically group in term of the number of patients with white blood cell counts $>12 \times 10^{9}$ in the initial regular blood test was the highest. Meanwhile patients with critically disease suffered fever for longer

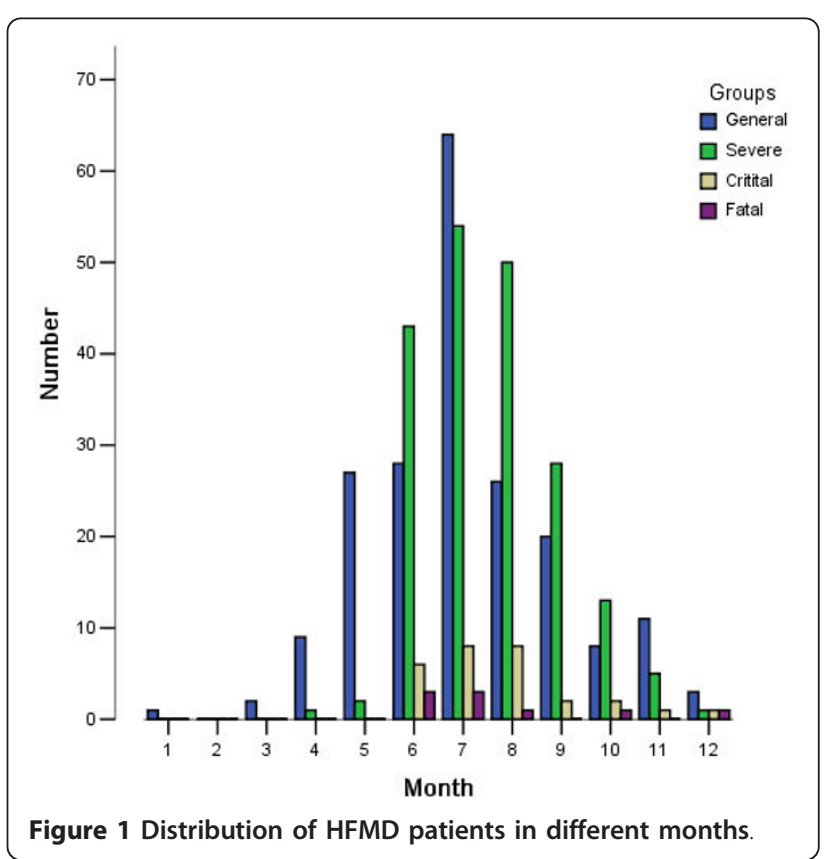


too. In total, 89/423 (21\%) EV71 cases were detected, with a higher detection rate in patients with more severe manifestations. A total of 68/423 (16.1\%) CA16 cases were detected, with a higher detection rate in patients less severely affected. Other enteroviruses (20/423, 4.7\%) were also detected, with no significant difference in distribution among the 4 groups. Patients who had experienced more severe symptoms ended up with worse outcome $(p<0.05)$. A detailed distribution of the neurological sequelae is provided in Table 1.

\section{Data characteristics of the clinical distribution of the enteroviruses}

Samples from the 423 hospitalized HFMD patients were examined, and $177(41.8 \%)$ tested positive for enterovirus. The results are shown in Figure 2.

Patients with EV71 infection were hospitalized earlier and for longer periods than those with CA16 infection. The difference was significant $(p<0.05)$. Patients with EV71 infection had the highest average temperature $\left(39.1^{\circ} \mathrm{C}\right)$, which was significantly different from the average temperatures in the other 2 groups $(p<0.05)$. Three critically ill patients had no rash. HFMD was confirmed in all patients with EV71 infection, although there was no significant difference compared to the other 2 groups $(p>0.05)$. EV71, CA16 and other enteroviruses are all capable of causing nervous system

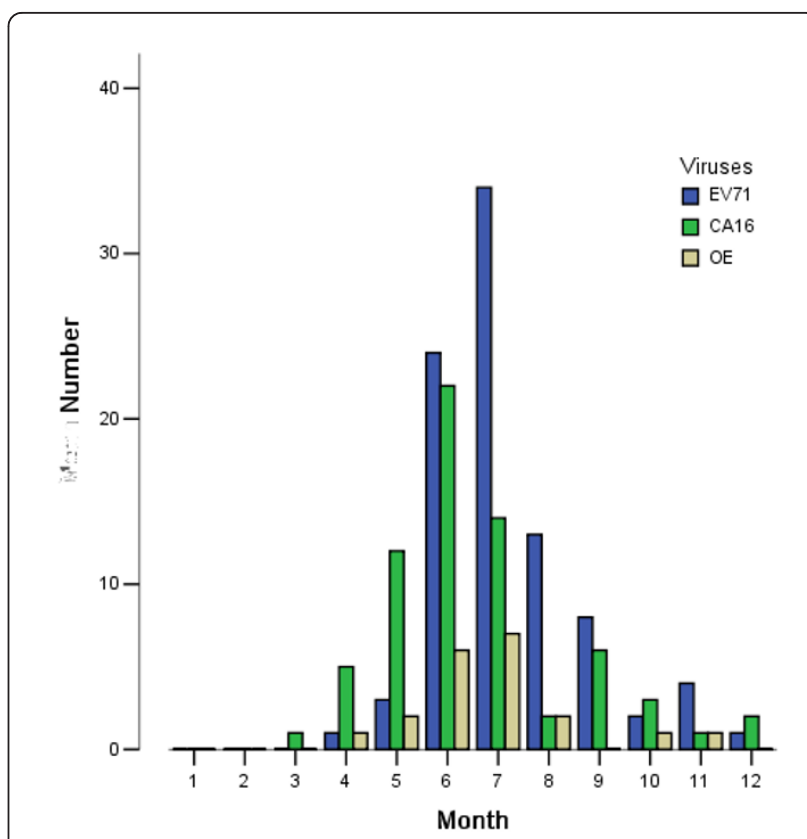

Figure 2 Pathogen distributions in different months.

damage and leading to a certain degree of neurologic dysfunction. There were 92 patients (52\%) with nervous system damage; the patients with EV71 were especially at risk (73\%). The incidence in the CA16 group was 19

Table 1 Analysis of the clinical data for 423 hospitalized patients

\begin{tabular}{|c|c|c|c|c|c|c|}
\hline & general & severely & critically & fatal & $p$ value & Total \\
\hline Case number $(n)$ & 189 & 197 & 28 & 9 & & 423 \\
\hline Number of cases in which a pathogen was detected (n) & $85(45.0 \%)$ & $71(36 \%)$ & $16(57.1 \%)$ & $5(55.6 \%)$ & 0.076 & $177(41.8 \%)$ \\
\hline Age $^{*}(\text { Years })^{(1}$ & $3.045 \pm 2.102$ & $2.546 \pm 1.730$ & $1.893 \pm 1.397$ & $2.056 \pm 1.509$ & 0.003 & \\
\hline Gender(male, $n$ ) & $125(66.1 \%)$ & $114(57.9 \%)$ & $25(89.3 \%)$ & $8(88.9 \%)$ & 0.003 & $272(64.3 \%)$ \\
\hline Region(from countryside, $\mathrm{n}$ ) & $116(61.4 \%)$ & $124(62.9 \%)$ & $23(82.1 \%)$ & $5(55.6 \%)$ & 0.185 & $268(63.4 \%)$ \\
\hline Time from onset to hospitalization(d) ${ }^{(1)}$ & $4.44 \pm 1.37$ & $3.89 \pm 1.26$ & $3.92 \pm 1.02$ & $3.81 \pm 0.96$ & 0.000 & \\
\hline Duration of hospitalization(d) ${ }^{2}$ & $8.85 \pm 2.46$ & $11.63 \pm 5.04$ & $49.51 \pm 33.20$ & $4.55 \pm 1.91$ & 0.000 & \\
\hline WBC $>12 \times 10^{9}(\mathrm{n})$ & $86(45.5 \%)$ & $121(61.4 \%)$ & $27(96.4 \%)$ & $8(88.9 \%)$ & 0.000 & $242(57.2 \%)$ \\
\hline Duration of initial fever(d) ${ }^{2}$ & $5.24 \pm 1.54$ & $6.33 \pm 1.94$ & $8.38 \pm 6.42$ & $6.42 \pm 2.25$ & 0.012 & \\
\hline Highest fever temperature $\left({ }^{\circ} \mathrm{C}\right)^{3}{ }^{3}$ & $38.76 \pm 0.46$ & $38.846 \pm 0.62$ & $39.206 \pm 0.51$ & $39.07 \pm 0.41$ & 0.032 & \\
\hline Hand or foot rash $(n)$ & $173(91.5 \%)$ & 183(92.9\%) & $23(82.1 \%)$ & $6(66.7 \%)$ & 0.017 & $385(91.0 \%)$ \\
\hline Oral rash $(\mathrm{n})$ & $121(64.0 \%)$ & 118(59.9) & $17(74.6)$ & $4(44.4 \%)$ & 0.608 & $260(61.5 \%)$ \\
\hline Buttock rash (n) & $76(40.2 \%)$ & $81(41.1 \%)$ & $6(21.4 \%)$ & $2(22.2 \%)$ & 0.159 & $165(39.0)$ \\
\hline No rash $(n)$ & & & $2(7.1 \%)$ & $1(11.1 \%)$ & 0.000 & $3(0.7 \%)$ \\
\hline EV71 (n) & $24(12.7 \%)$ & $47(23.9 \%)$ & $13(46.4 \%)$ & $5(55.6 \%)$ & 0.000 & $89(21 \%)$ \\
\hline CA16 (n) & $49(25.9 \%)$ & 18(9.1\%) & $1^{\oplus}(3.6 \%)$ & 0 & 0.000 & $68(16.1 \%)$ \\
\hline Other enteroviruses $(n)$ & $12(6.3 \%)$ & $6(3 \%)$ & $2(7.1 \%)$ & 0 & 0.369 & $20(4.7 \%)$ \\
\hline Patients with neurological dysfunction upon discharge $(n)$ & 0 & $2^{\circledR}(1 \%)$ & $11(39.3 \%)$ & & 0.000 & $13(3.1 \%)$ \\
\hline
\end{tabular}

(1)There is statistically significant difference between general group and the other 3 groups but no difference in comparison to the other 3 groups. (2)There is statistically significant difference between all groups. (3)There is no difference between general groups and severely group or critically group and fatal group, but there is significant difference between each one of the former and the latter two groups. \# There was no repeat counting in calculating the distribution of disease types. When neurogenic pulmonary edema or shock and brain stem encephalitis coexisted in the same patient, the former was counted. When neurogenic shock and pulmonary edema coexisted, pulmonary edema was counted. §The denominator of the fraction represents the cases examined, whereas the numerator represents the number of patients with this abnormality. aAmong the 5 fatal cases, 2 died of neurogenic pulmonary edema, 2 died of shock and 1 patient was declared brain-dead 
(27.9\%), and the incidence in patients infected with other enteroviruses was 1 (5\%); the differences among the 3 groups were significant $(p<0.05)$. Among the 13 patients with some neurologic dysfunction at discharge, 11 were infected with EV71, which was significantly different from the rates found in the other 2 groups $(p<$ $0.05)$. The 13 patients with neurologic dysfunction after treatment in the acute phase included the following: 5 patients with difficulty swallowing or coughing, a tendency to cough, a tendency to salivate and difficulty in getting rid of sputum; 5 patients with limb movement dysfunction, 2 of whom had grade-III muscle strength in both lower extremities and 3 of whom had grade-III muscle strength in a single limb and 1 patient with mental decline. After 3 months of mechanical ventilation in the pediatric intensive care unit (PICU), these patients showed stable vital signs and the presence of brain function; however, they still did not have regular, effective, spontaneous respiration. Two of these patients required prolonged mechanical ventilation and were transferred to local hospitals for further treatment. The 5 patients who died were infected with EV71; the difference in pathogen prevalence was significant $(p<0.05)$, as shown in Table 2 .

The pathogen distribution in the 92 cases of HFMD patients with nervous system damage is shown in Table 3 . Among the 3 groups, there was a significant difference observed in the prevalence of neurogenic pulmonary edema $(p<0.05)$. EV71 was the most frequently detected agent in patients for all the diseases studied.
Compared to CA16 or other enteroviruses, EV71 was most likely to cause all severe neurological diseases except for encephalitis. CA16 and other enteroviruses were the most common agents in encephalitis. EV71infected patients had a much higher incidence of clinical coma or limb movement disorder than the other 2 groups; these differences were significant $(p<0.05)$. Although EV71 infection was more likely to cause abnormal numbers of white blood cells in cerebrospinal fluid (CSF), there was no significant difference among the 3 groups $(p>0.05)$. In contrast to the results in Table 2, there were no significant differences among the different viruses in the frequency of neurological damage leading to dysfunction upon discharge or death $p>0.05$.

\section{Discussion}

Enterovirus infection is prevalent worldwide and usually prevales in warm weather, especially in summer and autumn, when it is associated with an increase in central nervous system infection [18]. In our study, the first patients with severe neurological impairment were admitted in April, and additional patients followed in June, July and August. Cases peaked in August and decreased afterward $[19,20]$. This seasonal distribution coincides with the trend in recent 3 years observed in Liaoning Province. In southern China, in Guangdong and Shandong, the flow of patients with severe symptoms started in March and April, possibly because of the warmer southern climate. Similar to recent studies

Table 2 Comparison of the clinical data from patients with different enteroviruses

\begin{tabular}{|c|c|c|c|c|c|}
\hline & EV71 & CA16 & OE & $p$ value & Total \\
\hline Total (n) & 89 & 68 & 20 & & 177 \\
\hline Gender (Male, n) & $52(58.4 \%)$ & $38(55.9 \%)$ & $14(70 \%)$ & 0.528 & $104(58.8 \%)$ \\
\hline Age $^{*}($ Years $)$ & $2.382 \pm 2.102$ & $2.588 \pm 1.860$ & $1.875 \pm 1.146$ & 0.347 & \\
\hline Region (from countryside, n) & $57(64 \%)$ & $41(60.3 \%)$ & $13(65 \%)$ & 0.868 & $111(62.3 \%)$ \\
\hline Time from onset to hospitalization $(d)^{2}$ & $3.258 \pm 1.176$ & $4 \pm 1.258$ & $3.6 \pm 1.353$ & 0.001 & \\
\hline Duration of hospitalization (d) & $14.337 \pm 17.796$ & $9.338 \pm 3.366$ & $8.1 \pm 3.354$ & 0.182 & \\
\hline WBC $>12 \times 10^{9}(n)$ & $51(57.3 \%)$ & $32(47.1 \%)$ & $11(55 \%)$ & 0.437 & $94(530.1 \%)$ \\
\hline $\mathrm{CRP}>8 \mathrm{mg} / \mathrm{dl}(\mathrm{n})$ & $4(4.5 \%)$ & $3(4.4 \%)$ & $1(5 \%)$ & 0.994 & $8(4.5 \%)$ \\
\hline Duration of initial fever(d) & $6.034 \pm 3.131$ & $5.706 \pm 1.684$ & $5.45 \pm 1.468$ & 0.547 & \\
\hline Highest fever temperature $\left({ }^{\circ} \mathrm{C}\right)^{(3)}$ & $39.144 \pm 0.563$ & $38.919 \pm 0.494$ & $38.92 \pm 0.618$ & 0.025 & \\
\hline Hand or foot rash $(n)$ & $81(91 \%)$ & $67(98.5 \%)$ & $20(100 \%)$ & 0.057 & $168(94.9 \%)$ \\
\hline Oral rash $(n)$ & $58(65.2 \%)$ & $50(73.5 \%)$ & $15(75 \%)$ & 0.451 & $123(69.5 \%)$ \\
\hline Buttock rash $(\mathrm{n})$ & $39(43.8 \%)$ & $28(41.2 \%)$ & $6(30 \%)$ & 0.525 & $73(41.2 \%)$ \\
\hline No rash $(\mathrm{n})$ & $3(2.2 \%)$ & 0 & 0 & 0.221 & $3(1.7 \%)$ \\
\hline Accompanied nervous system damage & $65(73 \%)$ & $19(27.9 \%)$ & $8(40 \%)$ & 0.000 & $92(52 \%)$ \\
\hline Patients with dysfunction upon discharge (n) & $11(12.4 \%)$ & $1(1.5 \%)$ & $1(5 \%)$ & 0.030 & $13(7.3 \%)$ \\
\hline Death (n) & $5(7.3 \%)$ & 0 & 0 & 0.030 & $5(2.8 \%)$ \\
\hline
\end{tabular}

*Patients aged 0-12 months were counted as being 0.5 years of age; patients aged 1-2 years were counted as being 1.5 years of age; patients aged 2-3 years were counted as being 2.5 years of age, etc. aAmong the 5 fatal cases, 2 patients died of neurogenic pulmonary edema, 2 died of shock, and 1 was diagnosed as being brain-dead. (2) Statistically significant difference between groups A and B but no difference in comparison to the other 2 groups. (3)There is statistically significant difference between group $A$ and groups $B$ and $C$ but no difference in comparison to the other 2 groups 
Table 3 Data analysis of the clinical neurological damage caused by different pathogens

\begin{tabular}{|c|c|c|c|c|c|}
\hline & EV71 & CA16 & $\mathrm{OE}$ & $p$ value & Total \\
\hline Total (n) & $65(70.7 \%)$ & $19(20.7 \%)$ & $8(8.7 \%)$ & & 92 \\
\hline Encephalitis ( $n)^{\#}$ & $39(60 \%)$ & $16(82.4 \%)$ & $6(75 \%)$ & 0.125 & $61(66.3 \%)$ \\
\hline Acute flaccid paralysis $(n)^{\#}$ & $2(3 \%)$ & $1(5.3 \%)$ & 0 & 0.772 & $3(3.3 \%)$ \\
\hline Brainstem encephalitis (n) & $8(12.3 \%)$ & $2(1.1 \%)$ & 0 & 0.572 & $10(10.9 \%)$ \\
\hline Neurogenic pulmonary edema $(n)^{\#}$ & $11(16.9 \%)$ & 0 & $1(12.5 \%)$ & 0.047 & $11(12 \%)$ \\
\hline Neurologic shock $(n)^{\#}$ & $5(7.7 \%)$ & 0 & $1(12.5 \%)$ & 0.215 & $6(6.5 \%)$ \\
\hline Limb shaking $(\mathrm{n})$ & $51(78.5 \%)$ & 15(78.9\%) & $6(75 \%)$ & 0.973 & $72(78.3 \%)$ \\
\hline Convulsion (n) & $21(32.3 \%)$ & $4(21.1 \%)$ & $2(25 \%)$ & 0.613 & $27(29.3 \%)$ \\
\hline Vomiting (n) & $42(64.6 \%)$ & $16(84.2 \%)$ & $7(87.5 \%)$ & 0.141 & $65(70.7 \%)$ \\
\hline Fatigue $(n)$ & $47(72.3 \%)$ & $17(89.5 \%)$ & $5(62.5 \%)$ & 0.219 & $69(75 \%)$ \\
\hline Coma (n) & $24(36.9 \%)$ & $2(10.5 \%)$ & $1(12.5 \%)$ & 0.046 & $27(29.3 \%)$ \\
\hline Limb movement disorder ( $n$ ) & $34(52.3 \%)$ & $3(15.8 \%)$ & $2(25 \%)$ & 0.010 & $39(42.4 \%)$ \\
\hline Urinary retention $(n)$ & $31(47.7 \%)$ & $6(31.6 \%)$ & $2(25 \%)$ & 0.266 & $39(42.4 \%)$ \\
\hline CSFWBC $>10 \times 10^{6} / L(n)^{\S}$ & $21 / 44(47.7 \%)$ & $8 / 14(57.1 \%)$ & $3 / 6(50 \%)$ & 0.828 & $25 / 64(39.1 \%)$ \\
\hline CSFPro $\geq 0.5 \mathrm{~g} / \mathrm{L}(\mathrm{n})^{\S}$ & 15/44(34.1\%) & $5 / 14(35.7 \%)$ & $2 / 6(33.3 \%)$ & 0.992 & $22 / 64(34.4 \%)$ \\
\hline Ambulatory EEG abnormality $(n)^{\S}$ & $17 / 32(53.1 \%)$ & $4 / 13(30.8 \%)$ & $1 / 5(20 \%)$ & 0.205 & $22 / 50(44 \%)$ \\
\hline Head MRI abnormality $(n)^{\S}$ & 13/32(40.6\%) & $5 / 15(33.3 \%)$ & $2 / 6(33.3 \%)$ & 0.685 & $20 / 53(37.7 \%)$ \\
\hline Patients with dysfunction upon discharge (n) & $11(16.9 \%)$ & $1(5.3 \%)$ & $1(12.5 \%)$ & 0.435 & $13(14.1 \%)$ \\
\hline Death $(n)^{a}$ & $5(7.7 \%)$ & 0 & 0 & 0.333 & $5(5.4 \%)$ \\
\hline
\end{tabular}

\# There was no repeat counting in calculating the distribution of disease types. When neurogenic pulmonary edema or shock and brain stem encephalitis coexisted in the same patient, the former was counted. When neurogenic shock and pulmonary edema coexisted, pulmonary edema was counted. §The denominator of the fraction represents the cases examined, whereas the numerator represents the number of patients with this abnormality. $a$ Among the 5 fatal cases, 2 died of neurogenic pulmonary edema, 2 died of shock and 1 patient was declared brain-dead

[21], males account for $64.3 \%$ of all patients in this study and are prone to severe symptoms. Although some studies reported that aged 4-9 years [22] or 5-10 years [23] may be the most susceptive period, we found, as in many studies [13] that patients under 5 years of age are at the highest risk, with most severe symptoms in the youngest patients. Rural preference is also observed, especially in patients with the most severe symptoms. We cautiously attribute this to the large rural population of China, as rural areas have poorer health care conditions and poorer environmental health; To make things worse, the water sanitation standard is low in rural China [24] (Table 1).

Among the 6,027 patients, 423 (7.0\%) were hospitalized; the major pathogen in HFMD has been reported to be CA16, which generally causes mild and self-limited symptoms. The main pathogens in Beijing in 2009 were CA16 (49.4\%) and EV71 (36.4\%) [25]. In recent outbreaks, however, EV71 infection has been the major cause of HFMD [26,27]. This virus was also the major pathogen in this study. EV71 accounted for 85 infections (45.0\%), and CA16 accounted for 71 (36\%). In severely ill and critically ill patients, EV71 accounts for an even higher proportion. It was responsible for all the 5 deaths, although the case number is limited. This distribution is different from previous observations (Table 1), possibly because the studied population includes only hospitalized patients with relatively severe symptoms.
EV71 caused neurologic damage in 65 patients, (70.7\%), and CA16 was the pathogen in 19 patients $(20.7 \%)$. It was possible that in Shenyang in 2010, EV71 was the major infective agent, but there is currently no official evidence to support this claim.

A different distribution of the gene in the population might explain why, in the past decade, EV71 has mainly caused disease in Taiwan, Malaysia, mainland China, Japan and other Asia-Pacific regions [28]. Taiwan researchers found that the histocompatibility leukocyte antigen (HLA)-A33 gene was correlated with susceptibility to virus infection and HLA-A2 was closely correlated with the occurrence of pulmonary edema. EV71 is neurotropic and can directly cause central neurological impairment; the virus replicates at the lesion site $[29,30]$. EV71 VP capsid proteins can bind to ornithine decarboxylase, gene-trap ankyrin repeats (GTARs) and other proteins expressed in neurons in the brain and cause cell injury [31]. Besides, it activates various cytokine pathways or bypasses signaling pathways to induce apoptosis or necrosis [32-35]. Studies have shown that in a mouse model, IgG antibodies generated during EV71 infection can pass the blood-brain barrier and cross-react with host brain tissue [36].

Other enteroviruses, such as ECHO7, ECHO14, the CVB group, CA6 and CA10, can all cause pediatric HFMD [37-39]. Other major enteroviruses in our studies include ECHO14, CVB and CVA10. In recent years, 
these viruses have shown an increasing trend as causes of HFMD; in particular, CVA6 and CVA 10 have recently emerged as pathogens of HFMD outbreaks in other countries, including Singapore and Finland $[40,41]$ With the exception of ECHO14, the echovirus serotypes identified and the CVB group viruses, including CVB3, CVB4 and CVB5, have been previously associated with cases of HFMD $[18,42]$.

The expression of the scavenger receptor class $B$, Member 2 (SCARB2) receptor protein can facilitate virus propagation in cells that normally are not susceptible to EV71 infection and also cause pathogenesis in these cells. CA16 can infect cells through the same pathway, but most other enteroviruses in group A do not depend on this ligand $[43,44]$. CA16 is generally associated with fewer neurologic complications, with the exception of infrequent cases of aseptic meningitis [45]. Neurological injuries caused by CA16 are relatively mild and deaths are especially rare. Therefore, the disease has attracted little attention $[46,47]$. However, we find that CA16 can also cause considerable neurological impairment. Although most affected patients had mild symptoms, three experienced severe, complicated nervous system injuries, two experienced brain-stem encephalitis and one suffered from AFP. The mechanism of pathogenesis, however, is not yet known, and it is not known whether neurons have receptors for EV71.

Neurogenic shock and neurogenic pulmonary edema occur simultaneously under most conditions and are highly dangerous; even if the circulation and lung function recover, brain and peripheral nervous function are more difficult to protect, and all of the 9 deaths in this study had neurogenic shock and/or neurogenic pulmonary edema. Death frequently occurs during the early stage of the disease (1st week), and brain death could occur even after circulation and respiratory functions are restored Even if the rescue is successful, the clinical recovery for these child patients is very slow. Some require prolonged mechanical ventilation to allow time for recovery; others require even longer ventilation to recover body movement and cranial nerve (glossopharyngeal nerve, vagus nerve or hypoglossal nerve) functions. Brainstem injury has long been considered a major cause of pulmonary edema $[21,48]$. In previous studies, however, pulmonary edema did not occur in monkeys with brainstem injury; therefore, other mechanisms may lead to EV71-related pulmonary edema [49]. Recent studies show that increased levels of the inflammatory cytokines interleukin-l (IL-1), interleukin-6 (IL-6), interleukin 10 (IL-10), interleukin 13 (IL13), interferon $\gamma($ IFN- $\gamma$ ) and tumor necrosis factor $\alpha$ (TNF- $\alpha$ ) and immune suppression of CD3 and CD4 Tcells and natural killer (NK) cells are related to pulmonary edema [50]. The release of various inflammatory factors stimulates a radical inflammatory response and the release of catecholamines, causing an increased release of interleukin-8 (IL-8) and changes in pulmonary capillary permeability, leading to pulmonary edema $[5,51,52]$.

The distribution of rash in HFMD patients infected by various viruses in this study showed no statistically significant differences, but three EV71-infected patients did not have any rash, and similar cases, as have been previously reported $[3,53]$. Convulsions, coma, body movement dysfunction and urinary retention mainly occur in EV71-infected patients because of their severe nervous system injuries. Cerebrospinal fluid, EEG and head MRI abnormalities also mainly occur in this group of patients. While this difference is not statistically significant, the limited sample size is probably to blame. As mentioned above, the disease progress rapidly, and apparent nervous system injury was observed at approximately 3 days. Body temperature rises to $>39.1^{\circ}$ $\mathrm{C}$ accompanied by convulsions, coma, limb movement disorder and severe complications such as neurogenic shock or neurogenic pulmonary edema. For patients with no rash, EV71 infection should be strongly suspected (Tables 2, 3).

\section{Conclusion}

The risk factors of life-threatening cases in hospitalized HFMD patients include young age, high fever, male gender and EV71 infection. HFMD patients infected with EV71 have a faster disease progression, higher fever and a higher incidence of limb movement disorder, coma, neurological damage, neurogenic pulmonary edema and death. Patients with neurological complications are prone to worse outcome and severe sequela. Generally, in HFMD patients, the symptoms of neurological damage caused by CA16 or other enteroviral infections are relatively mild, and the patients' prognoses are better. Severely ill patients, especially the critically and fatally ill patients are mostly infected by EV71; Nonetheless CA16 and other enteroviruses can also cause severe neurological symptoms in HFMD.

\section{Materials and methods}

An outbreak of pediatric hand, foot and mouth disease occurred in Liaoning Province of China in 2010. Patients with severe symptoms were hospitalized, and those in grave condition were treated in the pediatric intensive care unit (PICU). A retrospective analysis of this outbreak was conducted using general clinical data and data on clinical manifestations. Our study has been approved by the institutional review board of China Medical University. Pathogen test were carried out after informing and gaining permission from the patients' parents. The study focused on neurological 
complications and findings related to the pathogens and their correlations with HFMD in patients admitted to Shengjing Hospital of China Medical University between January 1st and December 31st 2010.

\section{Grouping}

The hospitalized patients were grouped by disease severity. A general patient was diagnosed with HFMD, and accompanied any one of the following symptoms: 1, lethargy, irritability or other behavioral signs of infection; 2, pneumonia and an increase in myocardial enzymes (particularly troponin, CPK-MB and their isozymes); 3, more than two incidences of vomiting accompanied by limb shaking; 4 , no improvement in symptoms 3 days after outpatient treatment or an unstable condition resulting in hospitalization. Severe group included patients presenting with obvious symptoms of nervous system involvement in HFMD, including complicating myoclonus, encephalitis, brainstem encephalitis and acute flaccid paralysis in addition to the basic symptoms of HFMD. The critically ill patients were those whose treatment was complicated by central respiratory failure or those who had brain-stem encephalitis, acute flaccid paralysis, neurogenic pulmonary edema, neurogenic shock or other severe symptoms and required endotracheal intubation and mechanical ventilation. Fatal patients included patients who died of respiratory and cardiac arrest and those who suffered brain death during treatment.

A second grouping was based on the pathogens detected: group EV71, group CA16 and group OE referring to patients infected with other enteroviruses.

\section{Diagnosis}

HFMD was defined as a febrile illness (temperature > $37.5^{\circ} \mathrm{C}$ ) accompanied by a papulovesicular rash of the oral mucosa, limb extremities and/or buttocks. Encephalitis was defined as persistent fever, altered consciousness, vomiting, limb shaking and convulsions with or without changes as seen in tests of cerebrospinal fluid and head imaging. Brainstem encephalitis was defined as brain-stem injury accompanied by lethargy and cranial nerve palsy with the clinical manifestations of cerebellar ataxia in addition to encephalitis. AFP was defined as the acute onset of loss of motor function in at least 1 skeletal muscle group (usually the limbs) associated with absent or diminished reflexes in the affected muscle group(s). Neurogenic pulmonary edema was defined as having an acute onset with early difficulty in breathing accompanied by a large amount of bloody, frothy sputum, auscultation of the lungs, high blood pressure, apparent pulmonary edema detected by chest X-Ray or bloody sputum drawn into an endotracheal tube. The term dysfunction is used in reference to patients who, after acute-phase treatment, still had a decreased ability to swallow and cough as well as decreased body movement and intelligence or those who had stable vital signs but lacked regular and effective autonomous respiration and relied on prolonged mechanical ventilation. All diagnoses of nervous system disease were made with the support of a pediatric neurologist.

\section{Pathogen detection}

Throat swab and/or stool specimens were collected from each child enrolled in the study. These samples were transported immediately at $4{ }^{\circ} \mathrm{C}$ to the Centers for Disease Control and Prevention (CDC, Shenyang, China) for the detection of EV71, CA16 and OE using the enterovirus nucleic acid detection kit (triplex realtime polymerase chain reaction assay; Guangzhou Daan Gene Co., Ltd., Guangzhou, China).

Viral RNA was isolated with Trizol reagent (Invitrogen, Carlsbad, CA). The cDNA synthesis was performed using the RNA PCR Kit (AMV) Ver. 3.0 (TaKaRa, Dalian, China). The $25 \mu \mathrm{L}$ PCR reaction mixture contained $1 \times$ buffer, $1.5 \mathrm{mM} \mathrm{MgCl}_{2}, 0.2 \mathrm{mM}$ dNTPs, 20 pmol forward primer and reverse primer and $20 \mathrm{pmol}$ fluorescence-labeled probe for each target (see Table 4), $1 \mathrm{U}$ of Taq polymerase and $5 \mu \mathrm{L}$ of cDNA. Multiplex real-time PCR was performed on 7,500 Real-Time PCR System (Applied Biosystems, Foster City, CA) with the following conditions: $3 \mathrm{~min}$ at $94^{\circ} \mathrm{C}$ followed by 40 cycles at $93^{\circ} \mathrm{C}$ for $15 \mathrm{~s}$ and $55^{\circ} \mathrm{C}$ for $45 \mathrm{~s}$.

\section{Statistical analysis}

Data analysis was conducted using the SPSS 13.0 software. Discrete variables are expressed as counts

Table 4 Nucleotide sequences of the specific primers and TaqMan probes used in this study

\begin{tabular}{|c|c|c|}
\hline Primer $\left(5^{\prime}-3^{\prime}\right)$ & & Probe $\left(5^{\prime}-3^{\prime}\right)$ \\
\hline $\begin{array}{l}\text { pan- } \\
\text { enterovirus }\end{array}$ & $\begin{array}{l}\text { Forward:GCAAGTCTGTGGCGGAACC Reverse: } \\
\text { TGTCACCATAAGCAGCCATGATA }\end{array}$ & $\begin{array}{l}\text { (FAM)- AATAACAGGAAACACGGACACCCAAAGTA } \\
\text { (TAMRA) }\end{array}$ \\
\hline EV71 & Forward:GTTCACCTACATGCGCTITGA Reverse:TGGAGCAATTGTGGGACAAC & (VIC)-TCTTGCGTGCACACCCACCG(TAMRA) \\
\hline CA16 & $\begin{array}{l}\text { Forward:CCTAAAGACTAATGAGACCACCC Reverse: } \\
\text { CTAAAGGCAGCACACAATTCG }\end{array}$ & (TEXAS RED)-CTTGTGCTTTCCAGTGTCGGTGCA(TAMRA) \\
\hline
\end{tabular}

The analysis of real-time PCR data: the threshold cycle (CT) value for each sample was calculated by determining the point at which the fluorescence exceeded the threshold limit, and the cut off was 35.1 determined by the ROC curve. The results of negative, positive and quality controls which were included in each experiment were within the normal range. 
(percentages), and continuous variables are expressed as means \pm standard deviation (SD). Differences in the demographic and clinical characteristics of the patient groups were assessed using the chi-square test for categorical variables. As the data showed a normal distribution, One-way ANOVA was adopted to analyze intersubgroup differences. As the data did not show normal distribution, Kruskal Wallis Test was adopted to analyze inter-subgroup differences. $p \leq 0.05$ was considered statistically significant.

\section{Abbreviations}

HFMD: Hand foot and mouth disease; EV71: Enterovirus71; CA: Coxsackie A; AFP: Acute flaccid paralysis; GBS: Gray-Barre syndrome; CRP: C reactive protein; PICU: Pediatric intensive care unit; CSF: Cerebrospinal fluid; EEG Ambulatory eeg; MRI: Magnetic resonance imaging; HLA: Histocompatibility leukocyte antigen; GTARs: Gene-trap ankyrin repeats; SCARB2: Scavenger receptor class $B$ Member 2 .

\section{Author details}

${ }^{1}$ Department of Pediatrics, Shengjing Hospital of China Medical University, Shenyang 110817, China. ${ }^{2}$ Department of Prevention, Shengjing Hospital of China Medical University, Shenyang 110817, China. ${ }^{3}$ Virus laboratory, Shengjing Hospital of China Medical University, Shenyang 110817, China. ${ }^{4}$ Department of Preventive Dentistry, School of Stomatology, China Medical University, Shenyang 110002, China.

\section{Authors' contributions}

LC have made substantial contributions to conception and design; XW collected, analysed and interpreted the data and wrote the manuscript the data; $Y L$ and $X X$ collected the data; $W L, L J$ and QY discussed and reviewed the manuscript; CR provided statistical analysis. All authors read and approved the final manuscript.

\section{Competing interests}

The authors declare that they have no competing interests.

Received: 11 September 2011 Accepted: 9 January 2012

Published: 9 January 2012

\section{References}

1. Robinson CR, Doane FW, Rhodes AJ: Report of an outbreak of febrile illness with pharyngeal lesions and exanthem: Toronto, summer 1957; isolation of group A Coxsackie virus. Can Med Assoc J 1958, 79:615-621.

2. Chan KP, Goh KT, Chong CY, Teo ES, Lau G, Ling AE: Epidemic hand, foot and mouth disease caused by human enterovirus 71, Singapore. Emerg Infect Dis 2003, 9:78-85.

3. Jee YM, Cheon DS, Kim K, Cho JH, Chung YS, Lee J, Lee SH, Park KS, Lee JH, Kim EC, Chung HJ, Kim DS, Yoon JD, Cho HW: Genetic analysis of the VP1 region of human enterovirus 71 strains isolated in Korea during 2000. Arch Virol 2003, 148:1735-1746.

4. Chan LG, Parashar UD, Lye MS, Ong FG, Zaki SR, Alexander JP, Ho KK, Han LL, Pallansch MA, Suleiman AB, Jegathesan M, Anderson LJ: Deaths of children during an outbreak of hand, foot, and mouth disease in sarawak, malaysia: clinical and pathological characteristics of the disease. for the outbreak study group. Clin Infect Dis 2000, 31:678-683.

5. Fujimoto T, Chikahira M, Yoshida S, Ebira H, Hasegawa A, Totsuka A, Nishio O: Outbreak of central nervous system disease associated with hand, foot, and mouth disease in Japan during the summer of 2000: detection and molecular epidemiology of enterovirus 71. Microbiol Immunol 2002, 46:621-627.

6. Tu PV, Thao NT, Perera D, Huu TK, Tien NT, Thuong TC, How OM, Cardosa MJ, McMinn PC: Epidemiologic and virologic investigation of hand, foot, and mouth disease, southern Vietnam, 2005. Emerg Infect Dis 2007, 13:1733-1741.
7. Yang F, Du J, Hu Y, Wang X, Xue Y, Dong J, Sun L, Li Z, Li Y, Sun S, Jin Q: Enterovirus coinfection during an outbreak of hand, foot, and mouth disease in Shandong, China. Clin Infect Dis 2011, 53:400-401.

8. De W, Changwen K, Wei L, Monagin C, Jin Y, Cong M, Hanri Z, Jun S: A large outbreak of hand, foot, and mouth disease caused by EV71 and CAV16 in Guangdong, China, 2009. Arch Virol 2011, 156:945-953.

9. Ho M, Chen ER, Hsu KH, Twu SJ, Chen KT, Tsai SF, Wang JR, Shih SR: An epidemic of enterovirus 71 infection in Taiwan. Taiwan enterovirus epidemic working group. N Engl J Med 1999, 341:929-935.

10. Liu CC, Tseng HW, Wang SM, Wang JR, Su IJ: An outbreak of enterovirus 71 infection in Taiwan, 1998: epidemiologic and clinical manifestations. $J$ Clin Virol 2000, 17:23-30

11. Zhang $Y$, Zhu Z, Yang W, Ren J, Tan X, Wang Y, Mao N, Xu S, Zhu S, Cui A, Zhang Y, Yan D, Li Q, Dong X, Zhang J, Zhao Y, Wan J, Feng Z, Sun J, Wang S, Li D, Xu W: An emerging recombinant human enterovirus 71 responsible for the 2008 outbreak of hand foot and mouth disease in Fuyang city of China. Virol J 2010, 7:94

12. Wang SM, Liu CC: Enterovirus 71: epidemiology, pathogenesis and management. Expert Rev Anti Infect Ther 2009, 7:735-742.

13. Chen SC, Chang HL, Yan TR, Cheng YT, Chen KT: An eight-year study of epidemiologic features of enterovirus 71 infection in Taiwan. Am J Trop Med Hyg 2007, 77:188-191.

14. Harvala H, McLeish N, Kondracka J, Mclntyre CL, McWilliam Leitch EC, Templeton K, Simmonds P: Comparison of human parechovirus and enterovirus detection frequencies in cerebrospinal fluid samples collected over a 5-year period in edinburgh: HPeV type 3 identified as the most common picornavirus type. J Med Virol 2011, 83:889-896.

15. Oberste MS, Maher K, Kilpatrick DR, Pallansch MA: Molecular evolution of the human enteroviruses: correlation of serotype with VP1 sequence and application to picornavirus classification. J Virol 1999, 73:1941-1948.

16. Hayward JC, Gillespie SM, Kaplan KM, Packer R, Pallansch M, Plotkin S, Schonberger LB: Outbreak of poliomyelitis-like paralysis associated with enterovirus 71. Pediatr Infect Dis J 1989, 8:611-616.

17. Alexander JP Jr, Baden L, Pallansch MA, Anderson LJ: Enterovirus 71 infections and neurologic disease-United States, 1977-1991. J Infect Dis 1994, 169:905-908

18. Thao NT, Ngoc NT, Tú PV, Thúy TT, Cardosa MJ, McMinn PC, Phuektes P: Development of a multiplex polymerase chain reaction assay for simultaneous identification of human enterovirus 71 and coxsackievirus A16. J Virol Methods 2010, 170(1-2):134-139.

19. Ooi MH, Wong SC, Lewthwaite P, Cardosa MJ, Solomon T: Clinical features, diagnosis, and management of enterovirus 71. Lancet Neurol 2010, 9:1097-1105

20. Lo SH, Huang YC, Huang CG, Tsao KC, Li WC, Hsieh YC, Chiu CH, Lin TY: Clinical and epidemiologic features of Coxsackievirus A6 infection in children in northern Taiwan between 2004 and 2009. J Microbiol Immunol Infect 2011, 44:252-257.

21. Wang SM, Liu CC, Tseng HW, Wang JR, Huang CC, Chen YJ, Yang YJ, Lin SJ, Yeh TF: Clinical spectrum of enterovirus 71 infection in children in southern Taiwan, with an emphasis on neurological complications. Clin Infect Dis 1999, 29:184-190.

22. Park SY, Kwon OS, Kim WY, Jung WJ, Ma SH, Kim SK: Epidemics of aseptic meningitis in Kyoungsangnamdo from March to October, 1997. Korean J Pediatr Infect Dis 1998, 5:104-114.

23. Wang SM, Ho TS, Shen CF, Liu CC: Enterovirus 71, one virus and many stories. Pediatr Neonatol 2008, 49:113-115.

24. Zhu Z, Zhu S, Guo X, Wang J, Wang D, Yan D, Tan X, Tang L, Zhu H, Yang $Z$, Jiang $X$, Ji $Y$, Zhang $Y, X u$ W: Retrospective seroepidemiology indicated that human enterovirus 71 and coxsackievirus A16 circulated wildly in central and southern China before large-scale outbreaks from 2008. Virol J 2010, 7:300.

25. Qu M, Li J, Jia L, Tan XJ, Gao ZY, Yan HQ, Guo J, Li XT, Li XY, Wang QY, $\mathrm{Xu}$ WB, Huang F: Etiology of hand-foot-and-mouth disease and genetic characteristics of Coxsackievirus A16 in Beijing, 2009. Bing Du Xue Bao 2010, 26:432-436.

26. Zhang J, Sun J, Chang Z, Zhang W, Wang Z, Feng Z: Characterization of hand, foot, and mouth disease in China between 2008 and 2009. Biomed Environ Sci 2011, 24:214-221.

27. Badran SA, Midgley S, Andersen P, Böttiger B: Clinical and virological features of enterovirus 71 infections in Denmark, 2005 to 2008. Scand J Infect Dis 2011, 43:642-648. 
28. Chang LY, Chang IS, Chen WJ, Huang YC, Chen GW, Shih SR, Juang JL, Shih HM, Hsiung CA, Lin TY, Huang LM: HLA-A33 is associated with susceptibility to enterovirus 71 infection. Pediatrics 2008, 122:1271-1276.

29. Nagata N, Shimizu H, Ami Y, Tano Y, Harashima A, Suzaki Y, Sato Y, Miyamura T, Sata T, Iwasaki T: Pyramidal and extrapyramidal involvement in experimental infection of cynomolgus monkeys with enterovirus 71. J Med Virol 2002, 67:207-16.

30. Wong KT, Munisamy B, Ong KC, Kojima H, Noriyo N, Chua KB, Ong BB, Nagashima K: The distribution of inflammation and virus in human enterovirus 71 encephalomyelitis suggests possible viral spread by neural pathways. J Neuropathol Exp Neurol 2008, 67:162-169.

31. Yeo WM, Chow VT: The VP1 structural protein of enterovirus 71 interacts with human ornithine decarboxylase and gene trap ankyrin repeat. Microb Pathog 2007, 42:129-137.

32. Chang SC, Lin JY, LO LY, Li ML, Shih SR: Diverse apoptotic pathways in enterovirus 71-infected cells. J Neurovirol 2004, 10:338-349.

33. Lin $H$, Lin TY, Juang JL: Abl deregulates Cdk5 kinase activity and subcellular localization in Drosophila neurodegeneration. Cell Death Differ 2007, 14:607-615.

34. Huang SC, Chang CL, Wang PS, Tsai Y, Liu HS: Enterovirus 71-induced autophagy detected in vitro and in vivo promotes viral replication. $J$ Med Virol 2009, 81:1241-1252

35. Tung WH, Hsieh HL, Yang CM: Enterovirus 71 induces COX-2 expression via MAPKs, NF-kappaB, and AP-1 in SK-N-SH cells: role of PGE (2) in viral replication. Cell Signal 2010, 22:234-246.

36. Jia CS, Liu JN, Li WB, Ma CM, Lin SZ, Hao Y, Gao XZ, Liu XL, Xu YF, Zhang LF, Qin C: The cross-reactivity of the enterovirus 71 to human brain tissue and identification of the cross-reactivity related fragments. Virol J 2010, 7:47.

37. Lin JY, Chen TC, Weng KF, Chang SC, Chen LL, Shih SR: Viral and host proteins involved in picornavirus life cycle. J Biomed Sci 2009, 16:103.

38. Peng D, Zhao D, Liu J, Wang X, Yang K, Xicheng H, Li Y, Wang F: Multipathogen infections in hospitalized children with acute respiratory infections. Virol J 2009, 6:155.

39. Blomqvist $S$, Klemola P, Kaijalainen S, Paananen A, Simonen ML, Vuorinen T, Roivainen M: Co-circulation of coxsackieviruses A6 and A10 in hand, foot and mouth disease outbreak in Finland. J Clin Virol 2010, 48:49-54.

40. Ang LW, Koh BK, Chan KP, Chua LT, James L, Goh KT: Epidemiology and control of hand, foot and mouth disease in Singapore, 2001-2007. Ann Acad Med Singapore 2009, 38:106-112.

41. Russo DH, Luchs A, Machado BC, Carmona Rde C, Timenetsky Mdo C: Echovirus 4 associated to hand, foot and mouth disease. Rev Inst Med Trop Sao Paulo 2006, 48:197-199.

42. Lum LC, Wong KT, Lam SK, Chua KB, Goh AY, Lim WL, Ong BB, Paul G, AbuBakar S, Lambert M: Fatal enterovirus 71 encephalomyelitis. J Pediatr 1998, 133:795-798.

43. Patel KP, Bergelson JM: Receptors identified for hand, foot and mouth virus. Nat Med 2009, 15:728-729.

44. Yamayoshi S, Yamashita Y, Li J, Hanagata N, Minowa T, Takemura T, Koike S: Scavenger receptor B2 is a cellular receptor for enterovirus 71. Nat Med 2009, 15:798-801.

45. Chang LY, Lin TY, Huang YC, Tsao KC, Shih SR, Kuo ML, Ning HC, Chung PW, Kang CM: Comparison of enterovirus 71 and coxsackie-virus A16 clinical illnesses during the Taiwan enterovirus epidemic, 1998. Pediatr Infect Dis J 1999, 18:1092-1096.

46. Goto K, Sanefuji M, Kusuhara K, Nishimura Y, Shimizu H, Kira R, Torisu H, Hara T: Rhombencephalitis and coxsackievirus A16. Emerg Infect Dis 2009, 15:1689-1691.

47. Wu Y, Yeo A, Phoon MC, Tan EL, Poh CL, Quak SH, Chow VT: The largest outbreak of hand; foot and mouth disease in Singapore in 2008: the role of enterovirus 71 and coxsackievirus A strains. Int J Infect Dis 2010, 14(12):e1076-1081.

48. McMinn P, Stratov I, Nagarajan L, Davis S: Neurological manifestations of enterovirus 71 infection in children during an outbreak of hand, foot, and mouth disease in Western Australia. Clin Infect Dis 2001, 32:236-242.

49. Tee KK, Lam TT, Chan YF, Bible JM, Kamarulzaman A, Tong CY, Takebe Y, Pybus OG: Evolutionary genetics of human enterovirus 71: origin, population dynamics, natural selection, and seasonal periodicity of the VP1 gene. J Virol 2010, 84:3339-3350.

50. Wang SM, Lei HY, Huang MC, Su LY, Lin HC, Yu CK, Wang JL, Liu CC: Modulation of cytokine production by intravenous immunoglobulin in patients with enterovirus 71-associated brainstem encephalitis. J Clin Virol 2006, 37:47-52.

51. Chang LY, Hsiung CA, Lu CY, Lin TY, Huang FY, Lai YH, Chiang YP, Chiang $B L$, Lee $C Y$, Huang LM: Status of cellular rather than humoral immunity is correlated with clinical outcome of enterovirus 71. Pediatr Res 2006, 60:466-471.

52. Lin YW, Chang KC, Kao CM, Chang SP, Tung YY, Chen SH: Lymphocyte and antibody responses reduce enterovirus 71 lethality in mice by decreasing tissue viral loads. J Virol 2009, 83:6477-683.

53. He SJ, Chen D, Zheng XQ, Wang CX, Huang AR, Jin YM, Yang HM, Xia C, Zhou AH, Wang $X$ : Three cases of enterovirus 71 infection with pulmonary edema or pulmonary hemorrhage as the early clinical manifestation. Zhonghua Er Ke Za Zhi 2008, 46:513-516.

doi:10.1186/1743-422X-9-8

Cite this article as: Xu et al:: Distribution of enteroviruses in hospitalized children with hand, foot and mouth disease and relationship between pathogens and nervous system complications. Virology Journal 2012 9:8.

\section{Submit your next manuscript to BioMed Central and take full advantage of:}

- Convenient online submission

- Thorough peer review

- No space constraints or color figure charges

- Immediate publication on acceptance

- Inclusion in PubMed, CAS, Scopus and Google Scholar

- Research which is freely available for redistribution 